Check for updates

Cite this: J. Mater. Chem. A, 2018, 6 , 24358

Received 5th September 2018 Accepted 13th November 2018

DOI: $10.1039 / c 8 t a 08631 a$

rsc.li/materials-a

\section{Atomically manipulated proton transfer energizes water oxidation on silicon carbide photoanodes $\uparrow$}

\author{
Hao Li, ${ }^{a}$ Huan Shang, ${ }^{b}$ Yuchen Shi, ${ }^{a}$ Rositsa Yakimova, ${ }^{a}$ Mikael Syväjärvi, ${ }^{a}$ \\ Lizhi Zhang (D) ${ }^{b}$ and Jianwu Sun iD *a
}

Surmounting the sluggish water oxidation kinetics beyond the hole-dominated thermodynamic effect is a topic of great scientific interest to establish fully renewable hydrogen technology from solar-powered water splitting. Herein, we demonstrate that the bottleneck of photoelectrochemical water oxidation can be overcome via atomic manipulation of proton transfer on the polar surfaces of silicon carbide ( $\mathrm{SiC}$ ) photoanodes. On the typical carbon-face SiC, where proton-coupled electron transfer governed the interfacial hole transfer for water oxidation, substantial energy loss was inevitable due to the highly activated proton-transfer steps. Via preferentially exposing the silicon-face, we enabled surfacecatalyzed barrierless $\mathrm{O}-\mathrm{H}$ breaking with a facile proton exchange and migration character. This mechanistically shifted the rate limiting step of water oxidation from sluggish proton-coupled electron transfer to a more energy-favorable electron transfer. The proof-of-concept study introduced here may open up new possibilities to design sophisticated photoelectrodes for an unbiased solar water splitting cell via surface engineering.

\section{Introduction}

Solar energy can provide sufficient power to meet the world's energy demand if it can be efficiently harvested. This is the very reason why photoelectrochemical (PEC) water splitting and $\mathrm{CO}_{2}$ reduction attract worldwide research interest as a promising sustainable technology for solar fuel production. ${ }^{\mathbf{1 - 4}}$ The PEC conversion of solar energy into chemical fuels is based on two half-reactions, namely, water oxidation and reduction reactions. The slow-rate oxygen evolution reaction (OER) at photoanodes in many cases is regarded as the bottleneck for PEC reactions, especially when photoanodes are coupled to many metals which can achieve a hydrogen evolution reaction at relatively low overpotentials. This is because the OER involves a four-electron process via several steps with high energy barriers $\left(2 \mathrm{H}_{2} \mathrm{O} \rightarrow \mathrm{O}_{2}\right.$ $\left.+4 \mathrm{H}^{+}+4 \mathrm{e}^{-}\right) \cdot{ }^{5,6}$ Despite the large number of methodologies which have been aiming to reduce the OER overpotential, including doping, surface modification, and nanostructure tuning, it still remains a challenge to design a highly active photoanode because the detailed mechanisms of the OER kinetics are still not fully understood.

${ }^{a}$ Department of Physics, Chemistry and Biology, Linköping University, 58183 Linköping, Sweden. E-mail: jianwu.sun@liu.se

${ }^{b}$ Key Laboratory of Pesticide \& Chemical Biology of Ministry of Education, Institute of Applied \& Environmental Chemistry, College of Chemistry, Central China Normal University, Wuhan 430079, P. R. China

$\dagger$ Electronic supplementary information (ESI) available. See DOI: 10.1039/c8ta08631a
Intrinsically, it is generally agreed that the OER in a typical PEC reaction is composed of the following four sequential proton-coupled electron transfer (PCET) steps: ${ }^{7-10}$

$$
\begin{gathered}
* \mathrm{H}_{2} \mathrm{O} \rightarrow * \mathrm{OH}+\mathrm{H}^{+}+\mathrm{e}^{-} \\
* \mathrm{OH} \rightarrow * \mathrm{O}+\mathrm{H}^{+}+\mathrm{e}^{-} \\
* \mathrm{O}+\mathrm{H}_{2} \mathrm{O}(\mathrm{l}) \rightarrow * \mathrm{OOH}+\mathrm{H}^{+}+\mathrm{e}^{-} \\
* \mathrm{OOH} \rightarrow \mathrm{O}_{2}+\mathrm{H}^{+}+\mathrm{e}^{-}
\end{gathered}
$$

where * denotes the surface adsorbed state, $\mathrm{e}^{-}$is the interfacial electron, $\mathrm{H}_{2} \mathrm{O}(\mathrm{l})$ is the liquid water, and $\mathrm{H}^{+}$is the dissociated proton. Among them, the first PCET $\left({ }^{*} \mathrm{H}_{2} \mathrm{O} \rightarrow{ }^{*} \mathrm{OH}+\mathrm{H}^{+}+\mathrm{e}^{-}\right)$, being characterized by both $\mathrm{O}-\mathrm{H}$ bond breaking associated proton-transfer (PT) and interfacial electron-transfer (ET), is envisioned as the rate-determining step. ${ }^{10}$ The first PCET of the OER has long been believed to be governed by ET, whose reaction thermodynamics is highly dependent on the redox level of the hole in the valence band (VB) of the photoanode. However, it cannot explain the ineffectiveness of the OER on many pristine semiconductors, including $\mathrm{TiO}_{2}, \mathrm{Fe}_{2} \mathrm{O}_{3}$ and $\mathrm{ZnO}$, whose VB positions perfectly match with that of water oxidation. ${ }^{11,12}$ The pioneering work done by Selloni and Liu groups, on the other hand, theoretically demonstrated that beyond the holedominated thermodynamic effect, strong kinetic effects concerned with PT were also essential for the OER. ${ }^{\mathbf{1 0 , 1 3 - 1 5}}$ For instance, the first PCET was demonstrated to be sequential with $\mathrm{PT}\left({ }^{*} \mathrm{H}_{2} \mathrm{O} \rightarrow{ }^{*} \mathrm{OH}^{-}+\mathrm{H}^{+}\right)$preceding ET $\left({ }^{*} \mathrm{OH}^{-} \rightarrow{ }^{*} \mathrm{OH}+\mathrm{e}^{-}\right)$; 
besides, an inherent high overpotential had arisen from highly activated $\mathrm{O}-\mathrm{H}$ oxidative cleavage and proton migration within the PT step, rather than the barrierless ET. As a proof of concept, this theory is consistent with the abundant theoretical and experimental findings that thermodynamic hole trapping by water was remarkably enhanced at high $\mathrm{pH}$, when the proton concentration of the electrolyte was low and only deprotonated surface states possessed appreciable energy to trigger the OER, all of which offer a possibility to accelerate the sluggish OER via modifying the delicate PT behavior. ${ }^{16-19}$

Silicon carbide ( $\mathrm{SiC}$ ) has emerged as a promising semiconductor for photocatalytic applications due to its superior chemical stability, high charge mobility, and suitable energy band positions that straddle the water redox potential. ${ }^{20,21}$ Most noticeably, SiC is receiving considerable attention as a novel biocompatible material due to its tunable surface water chemistry, particularly for the representative polar (carbon or silicon terminated) surfaces, which are commercially available. Depending on the terminated atoms ( $\mathrm{C}$ or $\mathrm{Si}$ ), the exposed surfaces display different atomic and electronic structures, which remarkably influence water adsorption, hydroxylation and wet oxidation behaviors. For example, the Si-face of SiC was theoretically proved to be capable of inducing water dissociation towards the formation of surface $\mathrm{Si}-\mathrm{OH}$ and $\mathrm{Si}-\mathrm{H}$ fragments, while the C-face displayed "inertness" to afford only molecular water adsorption, as demonstrated by Cicero and Amy et $a .^{22-24}$ In the light of this, the polar surfaces of SiC have emerged as an ideal platform to manipulate PT behavior for desirable water oxidation and understand more of the details of water oxidation mechanisms. In this study, we theoretically and experimentally demonstrate that the bottleneck of the OER can be overcome via atomic manipulation of PT over the SiC polar surfaces. By preferentially exposing the Si-face, we enabled surface-catalyzed barrierless $\mathrm{O}-\mathrm{H}$ breaking and proton exchange and migration within the PT step in the first proton removal reaction, which mechanistically shifted the sluggish rate-limiting step on the C-face to a more energy-favorable one, thus making the OER conductive at a very low overpotential even under neutral $\mathrm{pH}$ conditions. Mechanistic insights into the challenge of the PT scheme are provided on the basis of detailed theoretical and experimental results.

\section{Results and discussion}

\subsection{Theoretical study of water adsorption on SiC}

Density functional theory calculation was first used to model water adsorption and reaction on a prototypical SiC polar surface, the hexagonal 6H-SiC(0001) surface (Fig. 1a). On the Cterminated (0001) surface, $\mathrm{H}_{2} \mathrm{O}$ was found to remain floating above the surface at low coverage $(1 / 4 \mathrm{ML})$; even at higher coverage (when two $\mathrm{H}_{2} \mathrm{O}$ molecules were included into a supercell), water molecules preferred to optimize the internal hydrogen bond (HB) network without interacting with the Csurface (Fig. 1b). The charge density difference revealed an extremely weak HB-like interaction, as reflected by the appearance of charge localization in the region between a surface carbon atom and the $-\mathrm{OH}$ group of water. An entirely different
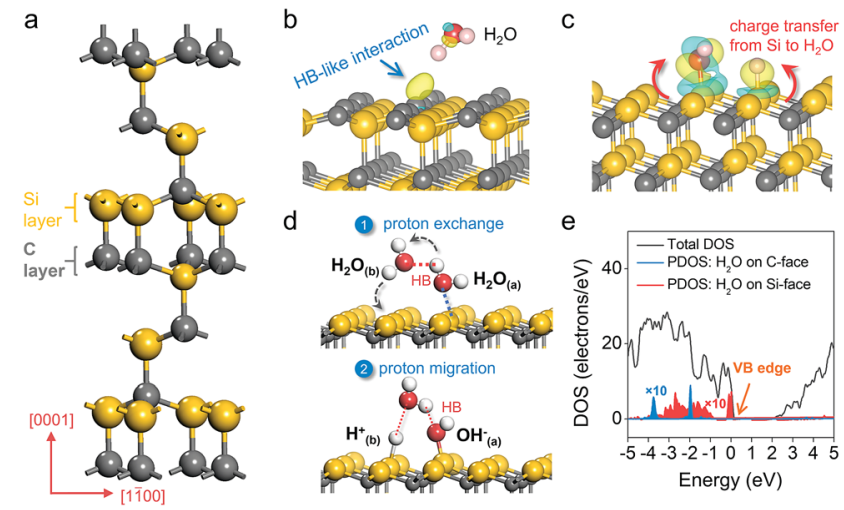

d
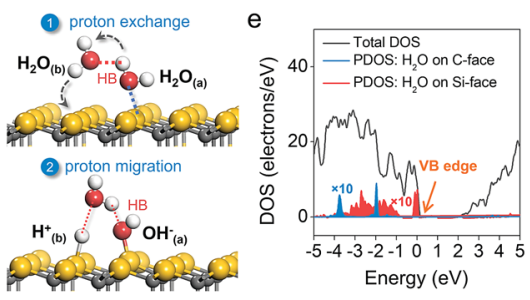

Fig. 1 Theoretical investigation of water adsorption and PT behavior on the $\mathrm{C}$ - and Si-polar surfaces of hexagonal $6 \mathrm{H}-\mathrm{SiC}$. (a) Unit cell of $6 \mathrm{H}-\mathrm{SiC}$. Adsorption of $\mathrm{H}_{2} \mathrm{O}$ on the (b) $\mathrm{C}$-surface and (c) $\mathrm{Si}$-face of $6 \mathrm{H}-$ $\mathrm{SiC}$. The yellow and blue isosurfaces represent charge accumulation and depletion in the space along with water adsorption, respectively. The isovalue is $0.005 \mathrm{au}$. (d) Proton exchange and migration on the Siface. Red dashed lines show the ordinary hydrogen bond $(\mathrm{HB})$ or hydrogen-like bond. (e) Partial density of states (PDOS) of water on the $\mathrm{Si}$-face and $\mathrm{C}$-face of $6 \mathrm{H}$-SiC with different adsorption structures. For the sake of presentation, the local contributions have been scaled by a factor of 10 .

picture of water adsorption was found when the Si-terminated (0001) surface was exposed. Irrespective of its initial orientation, $\mathrm{H}_{2} \mathrm{O}$ would diffuse to a $\mathrm{Si}-\mathrm{Si}$ dimer, where spontaneous dissociation took place $\left(\mathrm{H}_{2} \mathrm{O} \rightarrow \mathrm{OH}^{-}+\mathrm{H}^{+}\right)$with the $-\mathrm{OH}$ fragment bonding to one $\mathrm{Si}$ atom, and the $-\mathrm{H}$ fragment being transferred to another Si atom (Fig. 1c). Such water dissociation behavior was due to a thermodynamic need to stabilize the dangling bonds and minimize surface energy, ${ }^{23}$ as evidenced by the significant charge depletion on the Si-Si dimer and charge accumulation on dissociated water fragments with a large adsorption energy of $-3.36 \mathrm{eV}$ (Fig. 1c).

To explore the explicit first shell solvation effect, water adsorption at higher coverage was then modeled. When two $\mathrm{H}_{2} \mathrm{O}$ molecules were included into a supercell, we observed an interesting synchronous two proton exchange and migration phenomenon. Specifically, besides establishing a Lewis acidbase interaction with the $\mathrm{Si}$ surface, $\mathrm{H}_{2} \mathrm{O}_{(\mathrm{a})}$ formed a reliable $\mathrm{HB}$ with a nearby $\mathrm{H}_{2} \mathrm{O}_{(b)}$. Along with $\mathrm{H}_{2} \mathrm{O}_{(\mathrm{a})}$ dissociation, the $-\mathrm{H}_{\mathrm{a}}$ fragment, that was initially hydrogen-bonded, was transferred to $\mathrm{H}_{2} \mathrm{O}_{(\mathrm{b})}$, while $\mathrm{H}_{2} \mathrm{O}_{(\mathrm{b})}$ simultaneously released $\mathrm{a}-\mathrm{H}_{\mathrm{b}}$ fragment to a neighboring $\mathrm{Si}$ atom (Fig. 1d). Besides intermolecular proton exchange, proton exchange with a surface hydroxyl group on the Si-face along with water dissociation was also thermodynamically favorable (Fig. S1a $\dagger$ ). This interesting proton exchange and migration behavior remarkably promoted the proton transfer ability (from one $\mathrm{Si}-\mathrm{Si}$ dimer to another $\mathrm{Si}$ Si dimer) on the Si-terminated surface (Fig. 1d). When three $\mathrm{H}_{2} \mathrm{O}$ molecules were included into a supercell, two of them preferred to dissociate, while the third one formed a $\mathrm{HB}$ network with the two dissociated $\mathrm{H}_{2} \mathrm{O}$ molecules (Fig. $\mathrm{S} 1 \mathrm{~b} \dagger$ ). The HB network contained two strong HBs and one weak HB, representing a typical intimate interaction between a wetting surface with liquid water (Fig. S1c $\dagger$ ). Moreover, the formation of 
the $\mathrm{HB}_{3}$ lengthened the $\mathrm{Si}-\mathrm{H}$ bond from $1.50 \AA$ to $1.74 \AA$, simultaneously reducing the barrier of proton transfer to liquid water from $0.85 \mathrm{eV}$ to $0.32 \mathrm{eV}$. It has to be pointed out that when $\mathrm{H}_{2} \mathrm{O}$ was pushed to the C-face at a distance below $1.0 \AA$, it also dissociated on a C-C dimer. However, water dissociation on the C-face has to overcome a kinetic barrier of $1.41 \mathrm{eV}$, suggesting that such a reaction would not spontaneously occur even at higher temperature. To estimate the thermodynamics of water oxidation, we calculated the partial density of states (PDOS) of adsorbed water on different exposed surfaces of $6 \mathrm{H}-\mathrm{SiC}$. For $\mathrm{H}_{2} \mathrm{O}$ weakly bound to the C-face via a $\mathrm{HB}$, its PDOS was deeply embedded in the $\mathrm{VB}$, approximately $2.02 \mathrm{eV}$ lower compared to the $\mathrm{VB}$ edge of $6 \mathrm{H}-\mathrm{SiC}$, suggesting that hole transfer to the surface adsorbed $\mathrm{H}_{2} \mathrm{O}$ was thermodynamically hindered (Fig. 1e). However, dissociated water on the Si-face was apparently more active than molecular water on the C-face towards oxidation, as evidenced by its PDOS that almost overlapped the VB edge (Fig. 1e). ${ }^{25-27}$ This is consistent with the fact that oxidation of $\mathrm{OH}^{-}$to $\mathrm{O}_{2}$ is thermodynamically more favorable than the oxidation of $\mathrm{H}_{2} \mathrm{O}$ to $\mathrm{O}_{2}\left(E_{\mathrm{O}_{2} / \mathrm{OH}^{-}}=0.40 \mathrm{~V}\right.$ and $E_{\mathrm{O}_{2} / \mathrm{H}_{2} \mathrm{O}}=$ $1.23 \mathrm{~V}$ versus the reversible hydrogen electrode). ${ }^{16}$

\subsection{Experimental study of water adsorption on SiC}

The above theoretical scenarios revealed that the Si-face on $6 \mathrm{H}-$ SiC not only enabled barrier-less $\mathrm{O}-\mathrm{H}$ breaking on water adsorption, but also facilitated proton exchange and migration within the PT step, representing a key prerequisite for kinetically improved water oxidation. Meanwhile, from a thermodynamic point of view, water in the dissociated form $\left(\mathrm{OH}^{-}+\mathrm{H}^{+}\right)$ should be more active with holes than its molecular form, suggesting the potential superiority of the Si-face for water oxidation. To experimentally verify these calculation results, ntype C-terminated and Si-terminated $6 \mathrm{H}-\mathrm{SiC}$ films with device quality were grown on the C-face $6 \mathrm{H}-\mathrm{SiC}(000 \overline{1})$ and Si-face $6 \mathrm{H}-$ SiC(0001) substrates by chemical vapor deposition (CVD), respectively. ${ }^{28}$ The surface morphology of the as-grown films was examined by atomic force microscopy (Fig. S2 $\dagger$ ). Before evaluating its PEC performance, specific water adsorption structures on both $\mathrm{C}$ - and Si-face $6 \mathrm{H}-\mathrm{SiC}$ were investigated via Fourier-transform infrared (FTIR) spectroscopy in a designed reaction cell. The FTIR of pristine $\mathrm{C}$ - and Si-face $6 \mathrm{H}-\mathrm{SiC}$ exhibited two weak absorption bands spanning 3600$3800 \mathrm{~cm}^{-1}$ ascribed to residual hydroxyl groups stretching with no contaminants like $\mathrm{F}^{-}$and $\mathrm{NH}_{3}$. To avoid the possible interference of these hydroxyl groups, heavy water $\left(\mathrm{D}_{2} \mathrm{O}\right)$-saturated $\mathrm{Ar}$ gas was introduced to simulate water adsorption onto $6 \mathrm{H}-\mathrm{SiC}$ surfaces. After sufficient $\mathrm{D}_{2} \mathrm{O}$ adsorption, the reaction cell was thoroughly evacuated (to $\sim 10^{-6}$ mbar) at $120{ }^{\circ} \mathrm{C}$ (the boiling point of $\mathrm{D}_{2} \mathrm{O}$ is $101.4{ }^{\circ} \mathrm{C}$ ). No remarkable difference was observed on the $\mathrm{C}$-face before and after $\mathrm{D}_{2} \mathrm{O}$ adsorption, suggesting that $\mathrm{D}_{2} \mathrm{O}$ was weakly interacting with the C-face and thermal heating allowed full desorption of $\mathrm{D}_{2} \mathrm{O}$. In contrast, a strong $\nu(\mathrm{OD})$ stretching peak appeared at $2685 \mathrm{~cm}^{-1}$ (Fig.S3a $\dagger$ ). The reason why the newly appeared absorption band at $2685 \mathrm{~cm}^{-1}$ was indexed to -OD groups arising from $\mathrm{D}_{2} \mathrm{O}$ dissociation $\left(\mathrm{D}_{2} \mathrm{O} \rightarrow \mathrm{OD}^{-}+\mathrm{D}^{+}\right)$could be explained by two facts.
First, $\mathrm{D}_{2} \mathrm{O}$ was unlikely to exist on the $\mathrm{Si}$ face under continuous evacuation at $120{ }^{\circ} \mathrm{C}$, as the boiling point of $\mathrm{D}_{2} \mathrm{O}$ is $101.4^{\circ} \mathrm{C}$. Second, with further increasing the heating temperature in the reaction cell to $250{ }^{\circ} \mathrm{C}$, the strong absorption band at $2685 \mathrm{~cm}^{-1}$ experienced a slight decrease but was still clearly observed, suggesting that it should be attributed to strongly adsorbed -OD groups on $\mathrm{SiC}$ rather than weakly bound $\mathrm{D}_{2} \mathrm{O}$ (Fig. $\mathrm{S} 3 \mathrm{~b} \dagger$ ). ${ }^{26}$

To explore the possible proton exchange and migration scheme occurring on the Si-face, we further exposed the Si-face, which was pre-hydroxylated with -OD, to saturated $\mathrm{H}_{2} \mathrm{O}$ vapor. Following a transient water deposition at $298 \mathrm{~K}$, the saturated $\mathrm{H}_{2} \mathrm{O}$ vapor in the reaction cell was then gradually re-evacuated with the surface hydroxyl stretching being in situ monitored. Along with evacuation, the broad absorption band ranging from 2700 to $3700 \mathrm{~cm}^{-1}$ and the band at $1628 \mathrm{~cm}^{-1}$, which were respectively assigned to $\nu(\mathrm{OH})$ and $\sigma\left(\mathrm{H}_{2} \mathrm{O}\right)$, gradually decreased (Fig. 2a). ${ }^{5}$ However, IR absorption of $\nu(\mathrm{OD})$, which was supposed to remain chemically and thermally stable, experienced a synchronous decrease, suggesting that part of the -OD on the Si-face was consumed. Unexpectedly, concomitant with the $\nu$ (OD) decrease, a new absorption band at $1400 \mathrm{~cm}^{-1}$ gradually appeared, which was indexed to the bending absorption of $\sigma(\mathrm{HDO})$ (Fig. 2a). ${ }^{5}$ Since the IR absorption of the $\sigma$ (HDO) region could maintain high stability under even higher vacuum, the asformed HDO was believed to reside in the wetting layer, which interacted strongly with the hydroxyl groups on the Si-face via HBs (-Si-OH $\cdots$ HDO). Moreover, the almost linear decrease of $\nu(\mathrm{OD})$ and increase of $\sigma(\mathrm{HDO})$ along with evacuation time suggested that the consumption of -OD on the Si-face was directly associated with HDO generation (Fig. 2b). Conceivably, facile proton exchange and migration between -OD on the Si-face and outer layer $\mathrm{H}_{2} \mathrm{O}$ was supposed to dominate this process $(-\mathrm{Si}-\mathrm{OD}$ $+\mathrm{H}_{2} \mathrm{O} \rightarrow-\mathrm{Si}-\mathrm{OH} \cdots \mathrm{HDO}$ ) (Fig. S4a $\dagger$ ).

In order to more precisely specify the components in the above water film on the Si-face, electron-stimulated and photonstimulated desorption (ESD and PSD) techniques were carried out (Fig. 2c). ${ }^{29-32}$ In order to prepare a thin water film with a possible proton exchange layer on $6 \mathrm{H}-\mathrm{SiC}, \mathrm{D}_{2} \mathrm{O}$ was first deposited on $\mathrm{SiC}$ to ensure -OD hydroxylation, followed by evacuation (Fig. 2d). Then, 2-3 $\mathrm{ML} \mathrm{H}_{2} \mathrm{O}$ was deposited on the hydroxylated $6 \mathrm{H}-\mathrm{SiC}$ surfaces to enable the formation of a hybrid thin water film (Fig. 2d). On the Si-face of $6 \mathrm{H}-\mathrm{SiC}$, we were able to observe an abrupt $\mathrm{H}_{2} \mathrm{O}$ signal increase when the electron beam was turned on, followed by a rapid decay, indicating that stimulated $\mathrm{H}_{2} \mathrm{O}$ desorption directly happened on the water/vacuum interface (Fig. 2e). Besides, another signal corresponding to the proton exchange product of HDO was vividly witnessed on the Si-face, as depicted by a promotive increase but remarkably slower decrease (Fig. 2e). It is to be noted that an induction period appeared during stimulated HDO desorption. This is because electron-stimulated HDO desorption would occur only when the outer-layer $\mathrm{H}_{2} \mathrm{O}$ was largely desorbed (Fig. S4b $\dagger$ ), confirming that the proton exchange and migration region was located at the water $/ 6 \mathrm{H}-\mathrm{SiC}$ interface. As for the $\mathrm{C}$ face, it displayed an appreciably lower $\mathrm{H}_{2} \mathrm{O}$ desorption and no observable signal of $\mathrm{HDO}$, in agreement with its poor affinity to water as will be shown below. We also considered the effect of 
a

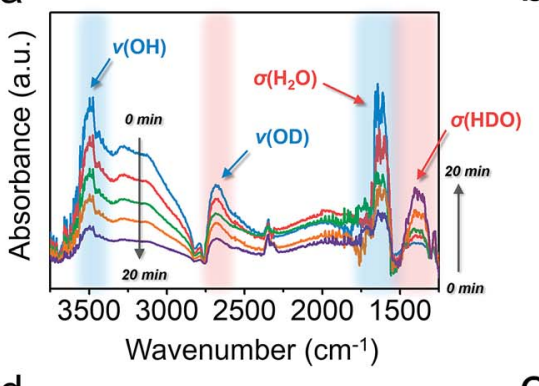

d

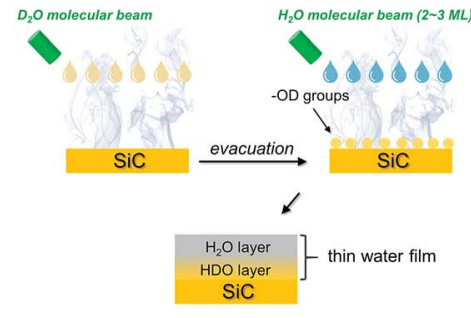

b
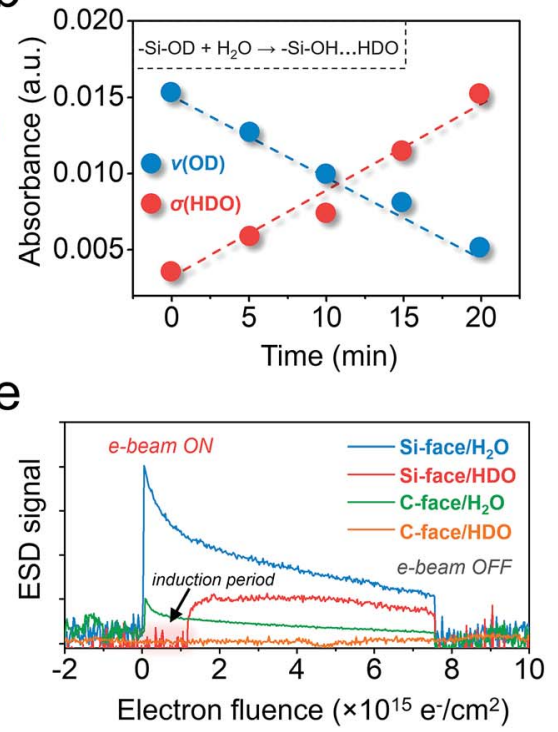

C

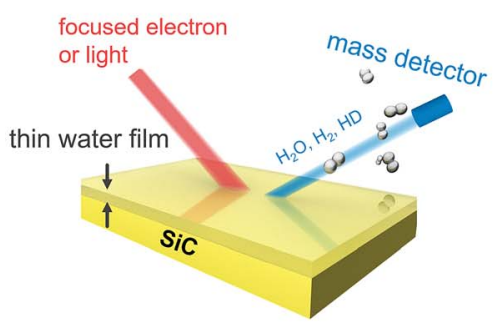

f

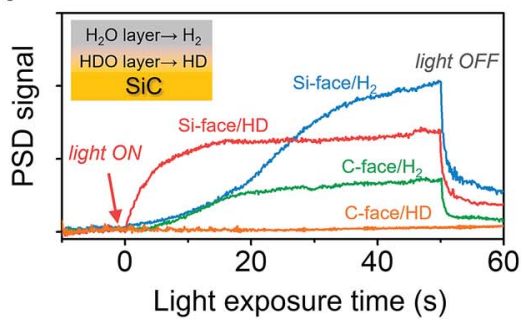

Fig. 2 Water adsorption behavior of the $\mathrm{C}$ - and $\mathrm{Si}$-face of $6 \mathrm{H}-\mathrm{SiC}$. (a) Dynamic change of the FTIR spectra of the $\mathrm{H}_{2} \mathrm{O}$-saturated $\mathrm{Si}$-face with -OD hydroxylation under continuous evacuation. (b) Absorbance change of the band of $\nu(\mathrm{OD})$ and $\sigma(\mathrm{HDO})$ along with evacuation time increase shown in (a). (c) Schematic illustration of the electron-stimulated or photon-stimulated desorption (ESD or PSD) technique for the investigation of water adsorption on $6 \mathrm{H}-\mathrm{SiC}$. (d) Preparation of a thin water film with a possible proton exchange layer for ESD and PSD analyses. (e) ESD signal of $\mathrm{H}_{2} \mathrm{O}$ and $\mathrm{HDO}$ versus electron fluence from the thin water film on the $\mathrm{C}$ - and $\mathrm{Si}$-face $6 \mathrm{H}-\mathrm{SiC}$. (f) PSD signal of $\mathrm{H}_{2}$ and $\mathrm{HD}$ production from the thin water film on the $\mathrm{C}$ - and $\mathrm{Si}$-face $6 \mathrm{H}-\mathrm{SiC}$.

light $(\lambda<400 \mathrm{~nm})$ illumination on the desorption manners of other related molecules, including $\mathrm{H}_{2}$ and HD. After the light was turned on, we successfully observed the desorption of $\mathrm{H}_{2}$ from the Si-face or C-face, arising from water splitting, which was pronounced, but sluggish, as it was saturated only after $40 \mathrm{~s}$ (Fig. 2f). Interestingly, another signal indexed to the proton exchange product of HD was perceived on the Si-face but was not observed on the C-face. Moreover, in stark contrast to the $\mathrm{H}_{2}$ signal, the HD signal increased more abruptly on the Si-face, reaching a maximum within $10 \mathrm{~s}$ (Fig. 2f). Since photoninduced water splitting preferentially occurred at the $6 \mathrm{H}-\mathrm{SiC} /$ water interface (Fig. S4c $\dagger$ ), the pronounced HD signal, derived from interfacial $\mathrm{HDO}$, indicated facile proton exchange and migration on the Si-face of $6 \mathrm{H}-\mathrm{SiC}$ was exceedingly beneficial for overall water splitting.

The macroscopic water-SiC interaction was also studied by water contact angle measurement. The C-face was found to be hydrophobic with a large contact angle of $95.8^{\circ}$, consistent with the weak molecular water adsorption behavior on this face (Fig. 3a). Differently, the water contact angle on the Si-face was only $36.7^{\circ}$, showing that the interaction between water and the Si-face should be much stronger (Fig. 3b). This peculiar hydrophilic character of the Si-face could be explained by the facile proton exchange and migration, as well as the strong $\mathrm{HB}$ network constructed between the inner and the outer layer of water, which facilitated the overall water adsorption. ${ }^{14,26}$ Enlightened by the above experimental results, we further prepared Si- and C-face $6 \mathrm{H}-\mathrm{SiC}$ photoanodes. A $200 \mathrm{~nm}$ thick $\mathrm{Al}$ layer was deposited on the backside of the highly conductive $6 \mathrm{H}-\mathrm{SiC}$ films $(0.8 \mathrm{~cm} \times 0.8 \mathrm{~cm})$ for making an ohmic contact for both the $\mathrm{Si}$ - and $\mathrm{C}$-face $6 \mathrm{H}-\mathrm{SiC}$ photoanodes, as evidenced by the linear $I-V$ curve (Fig. $3 \mathrm{c}$ and $\mathrm{S} 5 \dagger$ ). A three-electrode photoelectrochemical cell was used to evaluate the PEC performances of the C- and Si-face $6 \mathrm{H}-\mathrm{SiC}$ photoanodes in $0.5 \mathrm{M} \mathrm{pH} 6.8$ $\mathrm{Na}_{2} \mathrm{SO}_{4}$ solution. Both $6 \mathrm{H}-\mathrm{SiC}$ faces showed a low dark current in the linear sweep voltammetry scan, suggesting the absence of any chemical reactions in the dark. Under monochromatic light $\left(\lambda=410 \mathrm{~nm}, I_{0}=30 \mathrm{~mW} \mathrm{~cm}^{-2}\right)$, even though the C-face $6 \mathrm{H}-\mathrm{SiC}$ photoanode exhibited a low onset-potential of $0.15 \mathrm{~V}$ versus the a

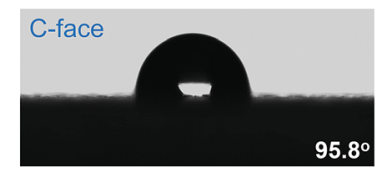

C

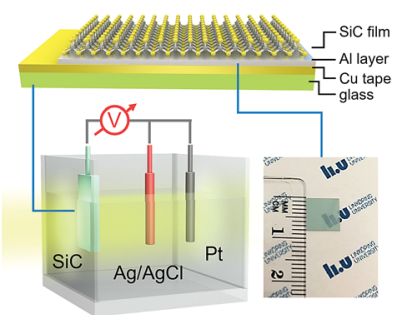

b

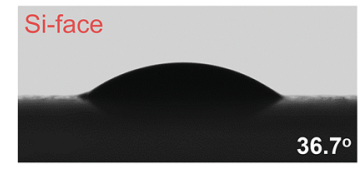

d

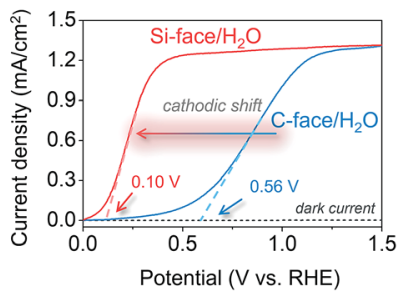

Fig. 3 Macroscopic water adsorption behavior and PEC performance of the $\mathrm{C}$ - and $\mathrm{Si}$-face of $6 \mathrm{H}-\mathrm{SiC}$. Water contact angles of the (a) $\mathrm{C}$ - and (b) Si-face $6 \mathrm{H}-\mathrm{SiC}$. (c) Schematic illustration of the PEC cell and photoelectrode structure. (d) Current density-voltage $(J-V)$ curves measured for the $6 \mathrm{H}-\mathrm{SiC}$ photoanodes in $0.5 \mathrm{M} \mathrm{pH} 6.8 \mathrm{Na}_{2} \mathrm{SO}_{4}$ solution under $410 \mathrm{~nm}$ monochromatic light. 
reversible hydrogen electrode (RHE) in the $J-V$ curve, a remarkable current increase occurred only from $0.56 \mathrm{~V}$, suggesting a typical sluggish water oxidation behavior due to the robust electron/hole recombination (Fig. 3d). As for the $6 \mathrm{H}-\mathrm{SiC}$ photoanode with the Si-face, the onset potential of water oxidation is $0 \mathrm{~V}$ versus $\mathrm{RHE}$ even under neutral conditions, indicating that the OER can occur without external bias. Besides, a precipitous photocurrent increase occurred at as low as $0.10 \mathrm{~V}$, which is a $0.46 \mathrm{~V}$ cathodic shift relative to the $6 \mathrm{H}-\mathrm{SiC}$ photoanode with the C-face (Fig. 3d). Moreover, a plateau appeared around $0.40 \mathrm{~V}$ over the Si-face with a saturated photocurrent density of 1.01 $\mathrm{mA} \mathrm{cm}{ }^{-2}$, which is limited to the light intensity. It is noteworthy that to reach the plateau of photocurrent density, C-face $6 \mathrm{H}-\mathrm{SiC}$ required a bias as large as $1.50 \mathrm{~V}$.

\subsection{Photoelectrochemical performance of SiC photoanodes}

The remarkably reduced energy for triggering the OER on the Siface could also be reflected in the applied bias photon-tocurrent efficiency (ABPE) in a two-electrode system. The maximum ABPE of $16.7 \%$ was achieved at an extremely low bias of $0.08 \mathrm{~V}$ on the Si-face under $410 \mathrm{~nm}$ monochromatic light, while it required a higher applied bias of $0.45 \mathrm{~V}$ to reach a comparable ABPE on the C-face (Fig. 4a). Correspondingly, the Si-face exhibited an obviously higher incident photo-to-current conversion efficiency than the $\mathrm{C}$-face in the wavelength region of 300-410 nm (above the bandgap of $6 \mathrm{H}-\mathrm{SiC}, 3.0 \mathrm{eV}$ ), even though they possessed almost the same light absorption capacity and identical optical band-edge absorption (Fig. S6 $\dagger$ ).

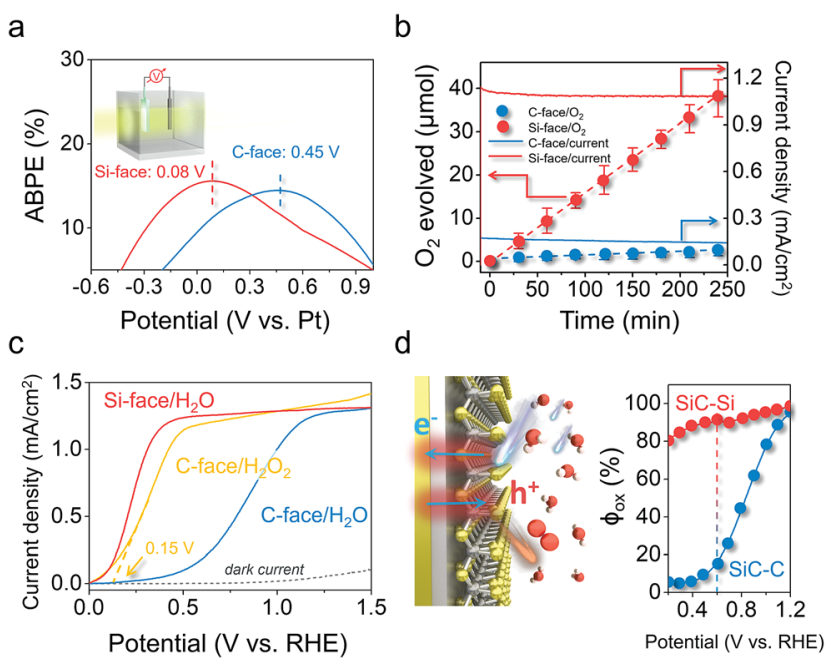

Fig. 4 Detailed PEC performance of the $6 \mathrm{H}-\mathrm{SiC}$ photoanodes with $\mathrm{Si}$ or $\mathrm{C}$-exposure. (a) ABPE of the $6 \mathrm{H}-\mathrm{SiC}$ photoanodes in a two-electrode system using $0.5 \mathrm{M} \mathrm{pH} 6.8 \mathrm{Na}_{2} \mathrm{SO}_{4}$ solution as the electrolyte. (b) Detected and calculated $\mathrm{O}_{2}$ production over the photoanodes at a bias of $0.4 \mathrm{~V}_{\mathrm{RHE}}$ in a three-electrode system. Solid lines show the corresponding $J-t$ curves in $0.5 \mathrm{M} \mathrm{pH} 6.8 \mathrm{Na}_{2} \mathrm{SO}_{4}$. Error bars represent standard deviation based on five independent experiments. (c) Comparison of $\mathrm{J}-\mathrm{V}$ curves measured over the $6 \mathrm{H}-\mathrm{SiC}$ photoanodes in $0.5 \mathrm{M} \mathrm{pH} 6.8 \mathrm{Na}_{2} \mathrm{SO}_{4}$ with and without in $0.1 \mathrm{M} \mathrm{H}_{2} \mathrm{O}_{2}$. (d) The quantum efficiency $\left(\varphi_{\text {ox }}\right)$ for water oxidation by surface holes determined from the data in (c) for $6 \mathrm{H}-\mathrm{SiC}$ photoanodes under PEC water oxidation conditions. Illumination: $410 \mathrm{~nm}$ monochromatic light.
Moreover, online $\mathrm{O}_{2}$ detection via gas chromatography (GC) confirmed that the photon-to-current conversion was mainly associated with stable $\mathrm{O}_{2}$ production with a current-to- $\mathrm{O}_{2}$ efficiency exceeding $90 \%$ under a bias of $0.4 \mathrm{~V}_{\mathrm{RHE}}$ in a threeelectrode system (Fig. 4b). Since both the C- and Si-face $6 \mathrm{H}-$ SiC films possessed identical doping concentrations and comparable Fermi levels (Fig. S7 $\dagger$ ), we believe the onset potential, the photocurrent density and the evolved $\mathrm{O}_{2}$ differences over the photoanode with different faces are more related to surface charge kinetics rather than the flat band potential, conductivity, or bulk recombination. To prove this point of view, we quantitatively determined the quantum efficiency $\left(\varphi_{\text {ox }}\right)$ of water oxidation by surface holes according to the method developed by Dotan et $a l .{ }^{33}$ The photocurrent density $(J)$ arising from the OER is theoretically described as $J=J_{\text {abs }} \varphi_{\text {sep }} \varphi_{\text {ox }}$, where $J_{\text {abs }}$ is the theoretical photocurrent density of $6 \mathrm{H}-\mathrm{SiC}$ assuming the absorbed photon conversion efficiency to be $100 \%$, and $\varphi_{\text {sep }}$ represents the charge separation yield of the photogenerated carriers (Fig. S8 $\dagger$ ). For an easily oxidized surrogate substrate like $\mathrm{H}_{2} \mathrm{O}_{2}$, surface recombination is completely suppressed with $\varphi_{\text {ox }}$ $\approx 1$. Therefore, when probing water oxidation using the same photoelectrode, $\varphi_{\text {ox }}$ can be calculated from the ratio of $J\left(\mathrm{H}_{2} \mathrm{O}\right)$ / $J\left(\mathrm{H}_{2} \mathrm{O}_{2}\right) \cdot{ }^{34}$ To obtain $J\left(\mathrm{H}_{2} \mathrm{O}_{2}\right)$, we performed linear sweep voltammetry over the photoanodes in the presence of $0.1 \mathrm{M} \mathrm{H}_{2} \mathrm{O}_{2}$ under the same conditions. Interestingly, the $J-V$ curve of the $6 \mathrm{H}$-SiC photoanode with the C-face performing $\mathrm{H}_{2} \mathrm{O}_{2}$ oxidation experienced a remarkable cathodic shift and sharp rise, resembling that of the $6 \mathrm{H}-\mathrm{SiC}$ photoanode with the $\mathrm{Si}$-face performing water oxidation (Fig. 4c). The calculated $\varphi_{\text {ox }}$ of the $\mathrm{C}$-face in our case was very low at a bias below $0.6 \mathrm{~V}$, reaching $80 \%$ at a higher bias of $1.0 \mathrm{~V}$ (Fig. $4 \mathrm{~d}$ ). As for the Si-face, it maintained a high $\varphi_{\text {ox }}$ approaching unity throughout the whole applied bias region (Fig. 4d). This demonstrated that separated holes on the Si-face more vividly participated in the surface water oxidation towards PEC oxygen evolution (Fig. 4d).

\subsection{Photoelectrochemical water oxidation kinetics on SiC photoanodes}

Apparently, the reason why the Si-face of $6 \mathrm{H}$-SiC displayed lower charge recombination kinetics and stronger reaction kinetics for water oxidation than the C-face was closely related to its specific atomic structure. According to our theoretical and experimental results, the unique water dissociation mode on the Si-face of $6 \mathrm{H}-\mathrm{SiC}$ with a facile proton exchange and migration character within the PT step was hypothesized to contribute substantially to its superior OER performance. To gain deep insight into the peculiar PT possibly occurring on the Si-face of the $6 \mathrm{H}-\mathrm{SiC}$ photoanode, we first evaluated the surface charge transfer kinetics via monitoring the photocurrent transient change under a progressively increasing bias. The transient photocurrent of the C-face photoanode showed a large spike in the initial stage at either low or high applied potential, followed by a multiexponential decrease due to the charge carrier recombination (Fig. 5a).

According to the work by Zhong and Zhang et al., such photocurrent decaying shape represented a characteristic OER 
a

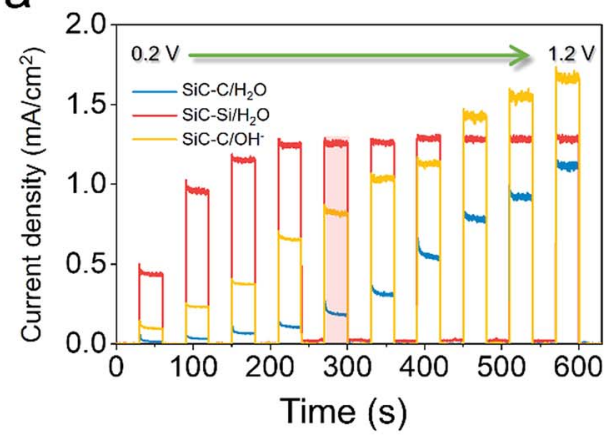

b

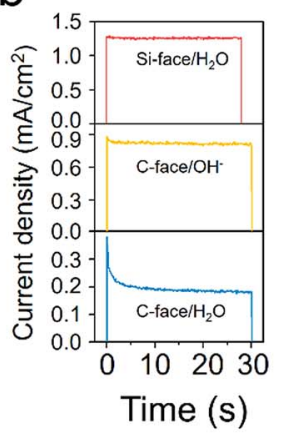

C

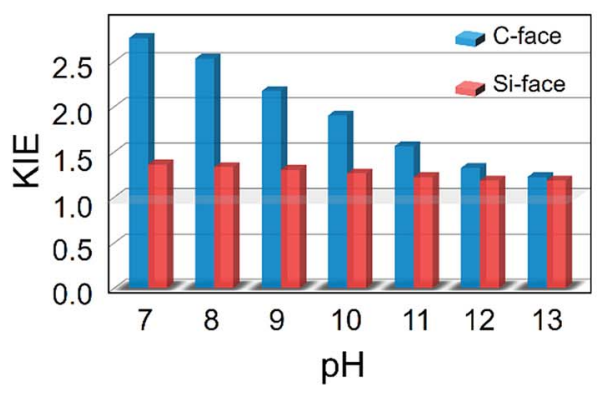

d

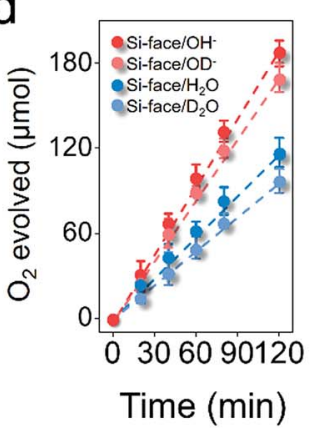
e
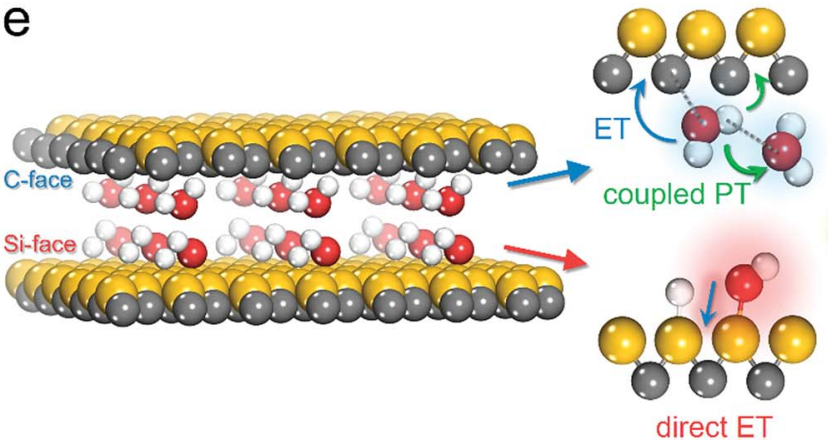

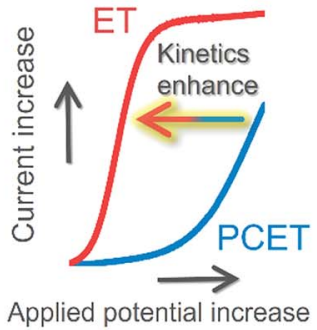

Applied potential increase

Fig. 5 Understanding the diverse mechanistic schemes of the photoelectrochemical OER on the $6 \mathrm{H}-\mathrm{SiC}$ electrodes. (a) J-V curves measured over the photoanodes in $0.5 \mathrm{M} \mathrm{Na}_{2} \mathrm{SO}_{4}$ or $0.1 \mathrm{M} \mathrm{NaOH}$ at a progressively increasing applied bias. (b) Photocurrent transient decaying in (a) at an applied bias of $0.6 \mathrm{~V}_{\text {RHE }}$ (highlighted in red). (c) The kinetic isotopic effect (KIE) in $\mathrm{H}_{2} \mathrm{O}$ and $\mathrm{D}_{2} \mathrm{O}$ with values calculated from the steady photocurrent ratio in $\mathrm{H}_{2} \mathrm{O}$ and $\mathrm{D}_{2} \mathrm{O}$ for photoanodes at various $\mathrm{pH}$ levels at an applied bias of $0.6 \mathrm{~V} \mathrm{~V}_{\mathrm{RH}}$. (d) Detected $\mathrm{O}_{2}$ production over the photoanodes at a bias of $0.4 \mathrm{~V}_{\mathrm{RHE}}$ under neutral conditions $\left(0.5 \mathrm{M} \mathrm{Na}_{2} \mathrm{SO}_{4}\right.$ as the electrolyte) and alkaline conditions $(0.1 \mathrm{M} \mathrm{NaOH}$ as the electrolyte). $\mathrm{D}_{2} \mathrm{O}$ and $\mathrm{NaOD}$ were used for $\mathrm{H} / \mathrm{D}$ isotopic labelling. Error bars represent standard deviation based on five independent experiments. (e) Schematic illustration of water oxidation kinetics increase due to the different electron-proton transfer pathways on the $\mathrm{C}$ - and Si-face of $6 \mathrm{H}-\mathrm{SiC}$. Illumination: $410 \mathrm{~nm}$ monochromatic light.

kinetic sluggishness due to the limited PT to water solvent or the catalytic surface during PCET steps. ${ }^{16,35}$ Typically, this major kinetic inadequacy could be circumvented in basic electrolytes, because $\mathrm{OH}^{-}$was easier to oxidize than $\mathrm{H}_{2} \mathrm{O} .^{35}$ As expected, the spikes were suppressed in $0.1 \mathrm{M} \mathrm{NaOH}$, suggesting the suppression of surface recombination when kinetic PT was no longer involved (Fig. 5a and b). In contrast, the photocurrent response over the Si-face was not only substantially higher even under neutral conditions than the C-face, but also showed higher stability, as characterized by the small spikes at low bias and square shape of chopped photocurrent at high bias (Fig. 5b). This observation suggested that PT was no longer a kinetic bottleneck on the Si-face $6 \mathrm{H}-\mathrm{SiC}$ photoanode in a neutral electrolyte. To acquire quantitative kinetic information on PT during the OER, the H/D isotopic labelling experiment was carried out. The steadystate photocurrent from the $J-t$ curves after $120 \mathrm{~s}$ of irradiation was used to calculate the kinetic isotopic effect (KIE) in $\mathrm{H}_{2} \mathrm{O}$ and $\mathrm{D}_{2} \mathrm{O}\left(\mathrm{KIE}=J\left(\mathrm{H}_{2} \mathrm{O}\right) / J\left(\mathrm{D}_{2} \mathrm{O}\right)\right)$ at different $\mathrm{pH}$ values. At a given moderate potential of $0.4 \mathrm{~V}_{\mathrm{RHE}}$, pronounced KIE values over 2.0 were witnessed on the C-face at low pH (7-9) (Fig. 5c). These characteristic KIE values indicated that oxidation of water in the molecular state was the dominant reaction with $\mathrm{O}-\mathrm{H}$ bond cleavage serving as the rate determining factor in the PCET steps of the OER. A similar mechanism was observed in biological and artificial molecular water oxidation systems. ${ }^{36,37}$ At higher $\mathrm{pH}(10-$
13), KIE values gradually decreased and became unity around 13 , suggesting that the oxidation of $\mathrm{OH}^{-}$governed by ET was the major reaction. Differently, the Si-face photoanode exhibited a small KIE at either low $\mathrm{pH}$ or high $\mathrm{pH}$, suggesting that the dominant step during the OER was ET. Moreover, we calculated the KIE values from the ratio of the evolved $\mathrm{O}_{2}$ gas under neutral or alkaline conditions $\left(\mathrm{KIE}=\mathrm{O}_{2}\left(\mathrm{H}_{2} \mathrm{O}\right) / \mathrm{O}_{2}\left(\mathrm{D}_{2} \mathrm{O}\right)\right.$ or $\mathrm{O}_{2}(\mathrm{NaOH}) /$ $\mathrm{O}_{2}(\mathrm{NaOD})$ ). Consistently, the Si-face photoanode exhibited distinct low KIE values around 1.2 under either neutral $\left(\mathrm{D}_{2} \mathrm{O}\right)$ or alkaline ( $\left.\mathrm{OD}^{-}, \mathrm{pH} 12\right)$ electrolytes (Fig. 5d). Meanwhile, even under stronger near UV light irradiation $\left(>80 \mathrm{~mW} \mathrm{~cm}^{-2}\right)$, the Siface photoanode was still able to maintain low KIE values towards the OER. ${ }^{38}$ This directly confirmed our theoretical prediction that on the Si-face of $6 \mathrm{H}-\mathrm{SiC}$, surface-catalyzed $\mathrm{O}-\mathrm{H}$ breaking on water adsorption towards the formation of $\mathrm{OH}^{-}$was a barrierless process, which also promoted proton exchange and migration within PT during the OER, thus suppressing surface charge recombination in case of PCET and enhancing overall OER kinetics (Fig. 5e).

\subsection{Construction of the zero-biased photoelectrochemical system}

The ultimate goal for practical PEC device designing is to construct an operative two-electrode system for overall water 
splitting without any external bias (Fig. 6a), which is denoted as zero-biased water splitting. ${ }^{39-41}$ The $6 \mathrm{H}-\mathrm{SiC}$ photoanode is a competitive material to enable such a conceptual design, because it can satisfy several key criteria, including high stability under strong acid or basic conditions and good transparency. Moreover, the Si-face of the $6 \mathrm{H}-\mathrm{SiC}(0001)$ surface with manipulated PT behavior exhibited high OER kinetics even under neutral conditions, with its maximum of ABPE (0.08 V) achieved at a potential being close to zero in a two-electrode system (Fig. 4a). Unfortunately, $6 \mathrm{H}-\mathrm{SiC}$ is a near-UV-light responsive semiconductor that largely limits its sufficient absorption to visible light. However, this proof-of-concept PT manipulation strategy we have explored over $6 \mathrm{H}-\mathrm{SiC}$ can be perfectly applied to cubic 3C-SiC, a more ideal polymorph of $\mathrm{SiC}$ for PEC application due to its electronic structure. ${ }^{42,43}$ As compared with $6 \mathrm{H}-\mathrm{SiC}, 3 \mathrm{C}-\mathrm{SiC}$ possesses an extended absorption edge around $500 \mathrm{~nm}$ and a suitable bandgap around $2.3 \mathrm{eV}$ that ensures ample solar light absorption, while simultaneously maintaining high potentials of the photogenerated charge carriers for water splitting reactions (Fig. 6b and c). Transparent yellowish single-crystalline 3C-SiC with the (111) polar surface exposed was grown via a high temperature sublimation epitaxial growth technique (Fig. 6c and S9†). Theoretical calculations demonstrated that water was preferentially dissociated on the Si-face of 3C-SiC (Fig. S10a and b $\dagger$ ). In a two-electrode system (3C-SiC as the photoanode and Pt as the counter electrode), Cface exposed 3C-SiC displayed a remarkably high photocurrent response as compared with $\mathrm{C}$-face $6 \mathrm{H}-\mathrm{SiC}$ in $0.5 \mathrm{M} \mathrm{pH} 6.8$ $\mathrm{Na}_{2} \mathrm{SO}_{4}$ solution under simulated solar light, while its ABPE reached a maximum only at $0.62 \mathrm{~V}$ (Fig. $6 \mathrm{~d}$ and S10c $\dagger$ ). Via preferentially exposing the Si-face, we found that the onset a

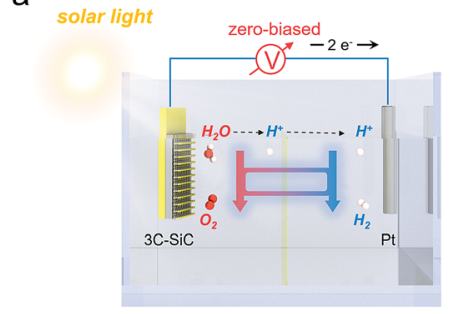

C

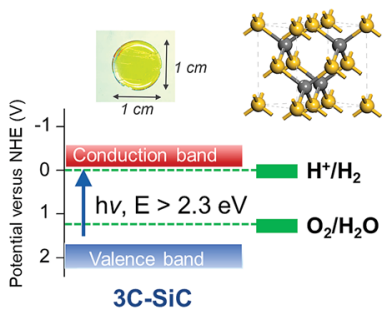

b

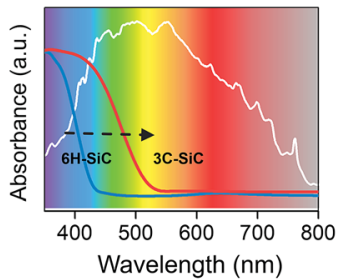

d

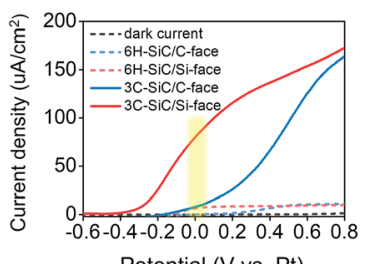

Potential (V vs. Pt)
Fig. 6 Constructing a zero-biased two-electrode PEC system based on $3 \mathrm{C}-\mathrm{SiC}$. (a) Schematic illustration of the zero-biased two-electrode PEC cell for water splitting. (b) UV-vis absorption spectra of $6 \mathrm{H}-$ and $3 \mathrm{C}-\mathrm{SiC}$. The white line shows the emission spectra of the simulated solar light. (c) Color, crystal structure, and band structure of the asprepared single-crystalline $3 \mathrm{C}-\mathrm{SiC}$ film. (d) $\mathrm{J}-V$ curves measured for $6 \mathrm{H}-\mathrm{SiC}$ and $3 \mathrm{C}-\mathrm{SiC}$ photoanodes with both $\mathrm{C}$ - and $\mathrm{Si}$-faces in $0.5 \mathrm{M}$ $\mathrm{pH} 6.8 \mathrm{Na}_{2} \mathrm{SO}_{4}$ under AM1.5G $100 \mathrm{~mW} \mathrm{~cm}^{-2}$ illumination. potential of 3C-SiC for the photoelectrochemical OER was remarkably shifted to $-0.4 \mathrm{~V}$, and the bias to achieve the maximum ABPE was reduced to $0.20 \mathrm{~V}$ in $0.5 \mathrm{M} \mathrm{pH} 6.8 \mathrm{Na}_{2} \mathrm{SO}_{4}$ solution (Fig. 6d and S10c $\dagger$ ). Under zero bias, an over 9 times photocurrent density increase was observed on the Si-face of 3C-SiC as compared with the C-face in the neutral $\mathrm{pH}$ electrolyte (Fig. S10d $\dagger$ ). Noteworthy, in $1 \mathrm{M} \mathrm{NaOH}$, where the sluggish $\mathrm{PT}$ was avoided, Si-face $3 \mathrm{C}-\mathrm{SiC}$ could maintain the maximum of $\mathrm{ABPE}$ at zero bias in the two-electrode system, while the ABPE of C-face 3C-SiC experienced a remarkable cathodic shift to $0.19 \mathrm{~V}$ (Fig. S10e and $f \dagger$ ). Optimizing the growth conditions to tune the doping and to enhance the crystalline quality with the aim of improving the photocurrent density is ongoing.

\section{Conclusions}

In conclusion, using switchable polar SiC surfaces as the platform, we demonstrated that the bottleneck of water oxidation could be overcome via manipulating PT at the surface molecular level. On the C-face of SiC, where PCET governed the interfacial hole transfer for water oxidation, substantial energy loss was inevitable due to the PT steps. Via preferentially exposing the Siface, we enabled surface-catalyzed barrier-less $\mathrm{O}-\mathrm{H}$ breaking, with a facile proton exchange and migration character. This mechanistically shifted the rate limiting step of water oxidation from sluggish PCET on the C-face to a more energy-favorable ET on the Si-face. The understanding gained in this study unravels the vital role that PT plays in determining the kinetics of water oxidation and may open up new possibilities for the design of sophisticated photoelectrodes and zero-biased PEC systems via surface engineering.

\section{Experimental section}

\subsection{Preparation of $6 \mathrm{H}-\mathrm{SiC}(0001)$ films and photoanodes}

The Si- and C-face $6 \mathrm{H}-\mathrm{SiC}$ epilayers were grown by CVD on highly $\mathrm{n}$-type doped $\mathrm{Si}$ - and $\mathrm{C}$-face 4 degree off-axis $6 \mathrm{H}$-SiC substrates, respectively. The thicknesses for both epilayers are around $30 \mu \mathrm{m}$. The Mott-Schottky measurements show an identical n-type doping concentration of $1.5 \times 10^{15} \mathrm{~cm}^{-3}$ for both Si- and C-face $6 \mathrm{H}-\mathrm{SiC}$ epilayers. Prior to the deposition of ohmic contacts on the backside of the films, they were chemically cleaned with acetone, ethanol, $\mathrm{H}_{2} \mathrm{O}: \mathrm{NH}_{3}: \mathrm{H}_{2} \mathrm{O}_{2}(5: 1: 1)$, $\mathrm{H}_{2} \mathrm{O}: \mathrm{HCl}: \mathrm{H}_{2} \mathrm{O}_{2}(6: 1: 1)$, hydrofluoric acid (HF) and water. The samples were then fixed on a sample holder and placed inside a vacuum chamber together with an aluminum (Al) source for evaporation. The vacuum chamber was connected to a device calibrated for metal evaporation within the system such that desired thicknesses could be input and applied power for the evaporation is set automatically. The resulting contacts were made of a $200 \mathrm{~nm}$ layer of $\mathrm{Al}$ on the backsides of the samples to ensure good ohmic behaviors, as seen in Fig. S5. $\uparrow$ The samples with deposited contacts on their backsides could be made into working electrodes by gluing them onto a piece of glass using copper tape. On some samples silver paste was used to further secure good contact between the copper and semiconductor. The whole electrode was then covered in epoxy resin, apart from 
the front surface of the semiconductor, which is supposed to be in contact with the electrolyte.

\subsection{Preparation of $3 \mathrm{C}-\mathrm{SiC}(111)$ films}

Bulk-like off-axis 3C-SiC(111) samples with a thickness of $\sim 1 \mathrm{~mm}$ were grown on 4 degree off-axis $4 \mathrm{H}$-SiC substrates (SiCrystal) by the sublimation epitaxial growth technique. ${ }^{\mathbf{4 4 , 4 5}}$ Then 300-400 $\mu \mathrm{m}$ thick free-standing 3C-SiC layers were obtained by polishing away the $4 \mathrm{H}-\mathrm{SiC}$ substrates and the interfacial layer. To remove contaminants and oxide from the surface, the 3C-SiC substrates were chemically cleaned using acetone, ethanol, $\mathrm{H}_{2} \mathrm{O}: \mathrm{NH}_{3}: \mathrm{H}_{2} \mathrm{O}_{2}(5: 1: 1), \mathrm{H}_{2} \mathrm{O}: \mathrm{HCl}: \mathrm{H}_{2} \mathrm{O}_{2}$ $(6: 1: 1)$, hydrofluoric acid (HF) and water. For making ohmic contact, $200 \mathrm{~nm}$ aluminum was deposited on the backside of each $3 \mathrm{C}-\mathrm{SiC}$ sample by similar thermal evaporation.

\subsection{Materials characterization}

A Nicolet iS50FT-IR spectrometer was used to in situ record diffuse reflectance FTIR spectra on SiC. A contact angle goniometer (OCA-20, DataPhysics, Germany) was adopted to measure the water contact angles on SiC surfaces. The phase structure of SiC was studied by powder X-ray diffraction (XRD) on a Rigaku D/MAX-RB diffractometer. Photo-generated $\mathrm{O}_{2}$ and $\mathrm{H}_{2}$ were detected using a GC equipped with a mass spectrometer (Trace 1300-ISQ, Thermo). The surface topography of Siand C-terminated samples was characterized with a $5 \times 5 \mu \mathrm{m}^{2}$ area using an atomic force microscope (AFM) in tapping mode. Electron-stimulated desorption (ESD) was carried out in an ultrahigh vacuum chamber $\left(3 \times 10^{-11} \mathrm{mbar}\right)$, equipped with a low-energy electron gun (100 eV), a mass spectrometer and a molecular beam for water $\left(\mathrm{H}_{2} \mathrm{O} / \mathrm{D}_{2} \mathrm{O}\right)$ deposition on the $\mathrm{SiC}$ substrate. Each individual scan on the SiC substrate was performed for $1 \mathrm{~s}$, delivering a fluence around $3 \times 10^{13} \mathrm{e}^{-}$per $\mathrm{cm}^{2}$. For photon-simulated desorption (PSD) measurement, an $\mathrm{Hg}$ lamp with a $400 \mathrm{~nm}$ short-pass filter (>400 nm light was cut off) was used that did not remarkably influence the temperature of the SiC substrate.

\subsection{PEC measurement}

The PEC setup consisted of a cell with a quartz window on its side and a lid with several holder positions for electrodes. Unless otherwise stated, $0.5 \mathrm{M} \mathrm{Na}_{2} \mathrm{SO}_{4}$ solution of $\mathrm{pH} 6.8$ was used as the electrolyte and $410 \mathrm{~nm}$ monochromatic light was used as the light source. Through the lid the electrodes were placed, the working electrode facing the quartz window, and the counter and reference electrodes close by. A Pt electrode was used as the counter and the $\mathrm{Ag} / \mathrm{AgCl}$ was used as the reference electrode. $J-V$ curves were measured using a scan rate of $10 \mathrm{mV}$ $\mathrm{s}^{-1}$ and RHE was calculated using the Nernstian relation $V_{\mathrm{RHE}}=$ $V_{\mathrm{Ag} / \mathrm{AgCl}}+0.0591 \mathrm{pH}+0.1976 \mathrm{~V}$. Before the measurement, the electrolyte was purged with Ar for $0.5 \mathrm{~h}$ to remove the dissolved $\mathrm{O}_{2}$. For the isotopic labelling experiment, $\mathrm{D}_{2} \mathrm{O}$ was used as the solvent and NaOD was used to adjust the $\mathrm{pH}$ of the electrolyte. To determine the ABPE, a two-electrode system (working electrode and counter electrode) was used. The solar conversion efficiency of PEC water oxidation was also evaluated using ABPE in a strict two electrode system according to the following equation:

$$
\mathrm{ABPE}=\left[\frac{\left|J_{\mathrm{ph}}\right|\left(\mathrm{mA} \mathrm{cm}^{-2}\right) \times\left(1.23-\left|V_{\mathrm{b}}\right|\right)(\mathrm{V})}{P_{\text {total }}\left(\mathrm{mW} \mathrm{cm} \mathrm{cm}^{-2}\right)}\right]
$$

where $J_{\mathrm{ph}}$ is the photocurrent density obtained under an applied bias $V_{\mathrm{b}}$ between the SiC electrode and the Pt counter electrode, $1.23 \mathrm{~V}$ is the standard water splitting reaction potential and $P_{\text {total }}$ is the incident light intensity of $410 \mathrm{~nm}$ monochromatic light $\left(30 \mathrm{~mW} \mathrm{~cm}^{-2}\right)$.

\subsection{Theoretical calculations}

All the above calculations were performed using the firstprinciples density functional theory (DFT) $+U$ calculations with the exchange-correlation energy functional, which were described by the generalized gradient approximation with the Perdew-Burke-Ernzerhof (PBE) exchange-correlation function. ${ }^{46}$ The projector augmented wave (PAW) method was applied to describe electron-ion interactions with a plane-wave cutoff energy of $400 \mathrm{eV} .^{47,48}$ In our simulations, the $(2 \times 2)$ supercells with a vacuum thickness of $20 \AA$ were built for Si- and C-terminated SiC surfaces, respectively. For optimization calculations, the energy and force converged to $10^{-5} \mathrm{eV}$ per atom and $0.02 \mathrm{eV}^{-1}$. A Monkhorst-Pack mesh was assigned as $5 \times 3 \times 1 .^{49}$ Transition states were determined by the nudged elastic band (NEB) method. ${ }^{\mathbf{5 0} 51}$ The interaction energy of the adsorbate water on the SiC surface was calculated as: $\Delta E=$ $E\left(\mathrm{H}_{2} \mathrm{O} / \mathrm{SiC}\right)-E(\mathrm{SiC})-E\left(\mathrm{H}_{2} \mathrm{O}\right) . E\left(\mathrm{H}_{2} \mathrm{O} / \mathrm{SiC}\right)$ is the total energy of the water adsorbed $\mathrm{SiC}$ system. $E(\mathrm{SiC})$ and $E\left(\mathrm{H}_{2} \mathrm{O}\right)$ are the energies of isolated $\mathrm{SiC}$ and $\mathrm{H}_{2} \mathrm{O}$ respectively. The charge density difference was calculated as: $\Delta \rho=\rho\left(\mathrm{H}_{2} \mathrm{O} / \mathrm{SiC}\right)-\rho\left(\mathrm{H}_{2} \mathrm{O}\right)$ $-\rho(\mathrm{SiC}) . \rho\left(\mathrm{H}_{2} \mathrm{O} / \mathrm{SiC}\right)$ is the density of the water adsorbed $\mathrm{SiC}$ system. $\rho\left(\mathrm{H}_{2} \mathrm{O}\right)$ and $\rho(\mathrm{SiC})$ are the densities of the two isolated subsystems.

\section{Conflicts of interest}

There are no conflicts to declare.

\section{Acknowledgements}

This work was supported by the Swedish Research Council (Vetenskapsrådet, Grant No. 621-2014-5461), the Swedish Research Council for Environment, Agricultural Sciences and Spatial Planning (FORMAS, Grant No. 2016-00559), the Swedish Foundation for International Cooperation in Research and Higher Education (STINT, Grant No. CH2016-6722), the ÅForsk foundation (Grant No. 16-399 and 18-370), and Stiftelsen Olle Engkvist Byggmästare (Grant No. 189-0243).

\section{Notes and references}

1 T. Hisatomi, J. Kubota and K. Domen, Chem. Soc. Rev., 2014, 43, 7520-7535.

2 K. Takanabe, ACS Catal., 2017, 7, 8006-8022. 
3 C. Ding, J. Shi, Z. Wang and C. Li, ACS Catal., 2017, 7, 675688.

4 T. W. Kim and K.-S. Choi, Science, 2014, 343, 990-994.

5 H. Sheng, H. Zhang, W. Song, H. Ji, W. Ma, C. Chen and J. Zhao, Angew. Chem., Int. Ed., 2015, 54, 5905-5909.

6 H. Dau, C. Limberg, T. Reier, M. Risch, S. Roggan and P. Strasser, ChemCatChem, 2010, 2, 724-761.

7 X. Zhang and A. Bieberle-Hütter, ChemSusChem, 2016, 9, 1223-1242.

8 M.-T. Nguyen, S. Piccinin, N. Seriani and R. Gebauer, ACS Catal., 2015, 5, 715-721.

9 J. Rossmeisl, Z.-W. Qu, H. Zhu, G.-J. Kroes and J. K. Nørskov, J. Electroanal. Chem., 2007, 607, 83-89.

10 J. Chen, Y.-F. Li, P. Sit and A. Selloni, J. Am. Chem. Soc., 2013, 135, 18774-18777.

11 R. Nakamura and Y. Nakato, J. Am. Chem. Soc., 2004, 126, 1290-1298.

12 P. Salvador, J. Phys. Chem. C, 2007, 111, 17038-17043.

13 Y.-F. Li, Z.-P. Liu, L. Liu and W. Gao, J. Am. Chem. Soc., 2010, 132, 13008-13015.

14 W.-N. Zhao and Z.-P. Liu, Chem. Sci., 2014, 5, 2256.

15 A. Valdés and G.-J. Kroes, J. Phys. Chem. C, 2010, 114, 17011708.

16 Y. Zhang, H. Zhang, H. Ji, W. Ma, C. Chen and J. Zhao, J. Am. Chem. Soc., 2016, 138, 2705-2711.

17 Z. Huang, Y. Lin, X. Xiang, W. Rodríguez-Córdoba, K. J. McDonald, K. S. Hagen, K.-S. Choi, B. S. Brunschwig, D. G. Musaev, C. L. Hill, D. Wang and T. Lian, Energy Environ. Sci., 2012, 5, 8923.

18 B. Klahr, S. Gimenez, F. Fabregat-Santiago, T. Hamann and J. Bisquert, J. Am. Chem. Soc., 2012, 134, 4294-4302.

19 B. Iandolo and A. Hellman, Angew. Chem., Int. Ed., 2014, 53, 13404-13408.

20 D. H. van Dorp, N. Hijnen, M. Di Vece and J. J. Kelly, Angew. Chem., Int. Ed., 2009, 48, 6085-6088.

21 C.-H. Hao, X.-N. Guo, Y.-T. Pan, S. Chen, Z.-F. Jiao, H. Yang and X.-Y. Guo, J. Am. Chem. Soc., 2016, 138, 9361-9364.

22 G. Cicero, G. Galli and A. Catellani, J. Phys. Chem. B, 2004, 108, 16518-16524.

23 G. Cicero, A. Catellani and G. Galli, Phys. Rev. Lett., 2004, 93, 016102.

24 F. Amy and Y. J. Chabal, J. Chem. Phys., 2003, 119, 6201-6209.

25 H. Sheng, H. Zhang, W. Song, H. Ji, W. Ma, C. Chen and J. Zhao, Angew. Chem., Int. Ed., 2015, 54, 5905-5909.

26 H. Li, J. Shang, H. Zhu, Z. Yang, Z. Ai and L. Zhang, ACS Catal., 2016, 6, 8276-8285.

27 H. Li, J. Li, Z. Ai, F. Jia and L. Zhang, Angew. Chem., Int. Ed., 2018, 57, 122-138.

28 T. Kimoto, A. Itoh and H. Matsunami, Appl. Phys. Lett., 1995, 66, 3645-3647.

29 C. D. Lane, N. G. Petrik, T. M. Orlando and G. A. Kimmel, J. Chem. Phys., 2007, 127, 224706.
30 N. G. Petrik and G. A. Kimmel, J. Phys. Chem. C, 2009, 113, 4451-4460.

31 Z. Wu, W. Zhang, F. Xiong, Q. Yuan, Y. Jin, J. Yang and W. Huang, Phys. Chem. Chem. Phys., 2014, 16, 7051.

32 Z. Zhang and J. T. Yates, Surf. Sci., 2016, 652, 195-199.

33 H. Dotan, K. Sivula, M. Grätzel, A. Rothschild and S. C. Warren, Energy Environ. Sci., 2011, 4, 958-964.

34 D. K. Zhong, S. Choi and D. R. Gamelin, J. Am. Chem. Soc., 2011, 133, 18370-18377.

35 D. K. Zhong and D. R. Gamelin, J. Am. Chem. Soc., 2010, 132, 4202-4207.

36 D. R. Weinberg, C. J. Gagliardi, J. F. Hull, C. F. Murphy, C. A. Kent, B. C. Westlake, A. Paul, D. H. Ess, D. G. McCafferty and T. J. Meyer, Chem. Rev., 2012, 112, 4016-4093.

37 M. Zhang, M. de Respinis and H. Frei, Nat. Chem., 2014, 6, 362-367.

38 T. Hisatomi, K. Takanabe and K. Domen, Catal. Lett., 2015, 145, 95-108.

39 D. Shao, Y. Cheng, J. He, D. Feng, L. Zheng, L. Zheng, X. Zhang, J. Xu, W. Wang, W. Wang, F. Lu, H. Dong, L. Li, H. Liu, R. Zheng and H. Liu, ACS Catal., 2017, 7, 5308-5315.

40 X. Wang, K.-Q. Peng, Y. Hu, F.-Q. Zhang, B. Hu, L. Li, M. Wang, X.-M. Meng and S.-T. Lee, Nano Lett., 2014, 14, 18-23.

41 Y. J. Jang, I. Jeong, J. Lee, J. Lee, M. J. Ko and J. S. Lee, ACS Nano, 2016, 10, 6980-6987.

42 Y. Liu, B. de Tymowski, F. Vigneron, I. Florea, O. Ersen, C. Meny, P. Nguyen, C. Pham, F. Luck and C. Pham-Huu, ACS Catal., 2013, 3, 393-404.

43 J. Wang, S. J. Xiong, X. L. Wu, T. H. Li and P. K. Chu, Nano Lett., 2010, 10, 1466-1471.

44 V. Jokubavicius, G. R. Yazdi, R. Liljedahl, I. G. Ivanov, J. Sun, X. Liu, P. Schuh, M. Wilhelm, P. Wellmann, R. Yakimova and M. Syväjärvi, Cryst. Growth Des., 2015, 15, 2940-2947.

45 V. Jokubavicius, G. R. Yazdi, R. Liljedahl, I. G. Ivanov, R. Yakimova and M. Syväjärvi, Cryst. Growth Des., 2014, 14, 6514-6520.

46 J. P. Perdew, K. Burke and M. Ernzerhof, Phys. Rev. Lett., 1996, 77, 3865-3868.

47 M. D. Segall, P. J. D. Lindan, M. J. Probert, C. J. Pickard, P. J. Hasnip, S. J. Clark and M. C. Payne, J. Phys.: Condens. Matter, 2002, 14, 2717-2744.

48 D. Vanderbilt, Phys. Rev. B: Condens. Matter Mater. Phys., 1990, 41, 7892-7895.

49 H. J. Monkhorst and J. D. Pack, Phys. Rev. B: Condens. Matter Mater. Phys., 1976, 13, 5188-5192.

50 G. Henkelman, B. P. Uberuaga and H. Jónsson, J. Chem. Phys., 2000, 113, 9901-9904.

51 N. A. Zarkevich and D. D. Johnson, J. Chem. Phys., 2015, 142, 024106. 